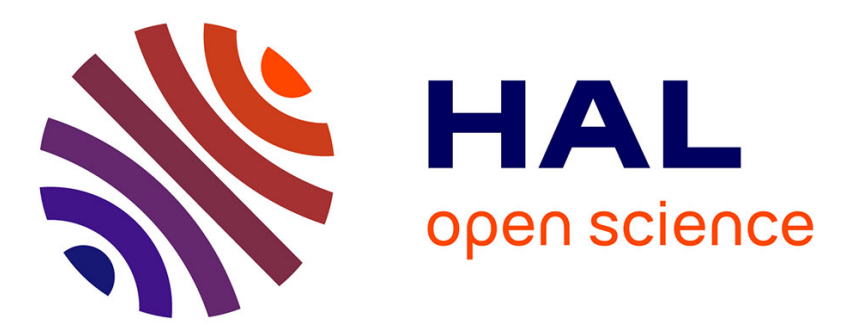

\title{
Microchannel conductivity measurements in microchip for on line monitoring of dephosphorylation rates of organic phosphates using paramagnetic-beads linked alkaline phosphatase \\ Mohammed Kechadi, Bruno Sotta, Jean Gamby
}

\section{To cite this version:}

Mohammed Kechadi, Bruno Sotta, Jean Gamby. Microchannel conductivity measurements in microchip for on line monitoring of dephosphorylation rates of organic phosphates using paramagneticbeads linked alkaline phosphatase. Talanta, 2015, 132, pp.785 - 789. 10.1016/j.talanta.2014.10.011. hal-01085012

\section{HAL Id: hal-01085012 \\ https://hal.science/hal-01085012}

Submitted on 20 Nov 2014

HAL is a multi-disciplinary open access archive for the deposit and dissemination of scientific research documents, whether they are published or not. The documents may come from teaching and research institutions in France or abroad, or from public or private research centers.
L'archive ouverte pluridisciplinaire $\mathbf{H A L}$, est destinée au dépôt et à la diffusion de documents scientifiques de niveau recherche, publiés ou non, émanant des établissements d'enseignement et de recherche français ou étrangers, des laboratoires publics ou privés. 


\title{
Microchannel conductivity measurements in microchip for on line monitoring of dephosphorylation rates of organic phosphates using paramagnetic-beads linked alkaline phosphatase
}

\author{
Mohammed Kechadi, ${ }^{\mathrm{b}}$ Bruno Sotta ${ }^{\mathrm{c}}$ and Jean Gamby ${ }^{\mathrm{a}, \mathrm{b}, \text { * }}$ \\ ${ }^{a}$ CNRS, UMR 8235, LISE, F-75005, Paris, France \\ ${ }^{b}$ Sorbonne Universités, UPMC Univ Paris 06, UMR 8235, Laboratoire Interfaces et Systèmes \\ Electrochimiques, F-75005, Paris, France \\ ${ }^{d}$ Sorbonne Universités, UPMC Univ Paris 06, UMR 7622, Laboratoire Biologie des Semences, 4 \\ Place Jussieu, F-75005 Paris, France
}

\footnotetext{
* Corresponding Author

jean.gamby@upmc.fr: $\quad$ tel: +33144273640 fax: ++33144274074
} 


\begin{abstract}
This paper presents the use of polymer coated microelectrodes for the realtime conductivity monitoring in a microchannel photoablated through the polymer without contact. Based on this strategy, a small conductometry sensor has been developed to record in time conductivity variation when an enzymatic reaction occurs through the channel. The rate constant determination, $k_{2}$, for the dephosphorylation of organic phosphate-alkaline phosphatase-superparamagnetic beads complex using chemically different substrates such as adenosine monoesterphosphate, adenosine diphosphate and adenosine triphosphate was taken as an example to demonstrate selectivity and sensivity of the detection scheme. The $k_{2}$ value measured for each adenosine phosphate decreases from 39 to $30 \mathrm{~s}^{-1}$ in proportion with the number (3,2 and 1) of attached phosphate moiety, thus emphasizing the steric hindrance effect on kinetics.
\end{abstract}

Keywords: microchip; admittance; conductometry; enzyme; dephosphorylation 


\section{Introduction}

In the recent years, the growing development of microfluidic systems for ultrasensitive medical diagnostics on chip has been integrated as new module for smartphone application.[1],[2, 3] For this challenge, electrical transduction methods are more suitable for the detection of ionic species (oxidable or reducable) because of their high sensitivity and no need labelling step is required.[4],[5],[6] The relevance of electrochemical detection on microchips with improvement of micro nanoelectrode fabrication [7],[8],[9],[10],[11], [12] has been widely proven, including the application of amperometric detection [13], [14, 15],[16], and potentiometric.[17],[18],[19] However, contactless to the microelectrodes as electrical detection scheme with the electrolyte is the most promising [20, 21],[22],[23]. Indeed, the non contact measurement scheme with two microelectrodes galvanically isolated has several advantages conversely to the contact mode. For instance, in the microelectrophoresis field, [23-25] some drawbacks due to interference associated with the contacting electrode and the electrolyte, such as non specific adsorption, degradation or electrode corrosion, bubbles formation due to the water electrolysis, are suppressed by measuring the contactless conductivity of the electrolyte in the separation channel. Moreover, this configuration enables an electronic decoupling as the detector for measuring conductivity is effectively isolated from the high voltage applied in the same channel for the separation and ions migration. Another significant advantage is that the networking and alignment of the detector are simplified making it possible electrode positioning anywhere in the separation channel.

A new strategy for microelectrode without contact with the streaming electrolyte in the microchannel has been developed in the recent years. [26,27],[28] It differs from the previous strategies by the use of microelectrodes that are embedded in an insulating dielectric polymer (PET) thanks to laser photoablation process. Indeed, the laser permits a close positioning of the microchannel with a near distance to the fluidic channel bottom equals to 2-5 $\mu \mathrm{m}$. In this work the capacitive effect originates from coupling between the electronic charges (two planar microband electrodes) on one side of the dielectric PET layer and the ionic charges (streaming electrolyte in microchannel) in contact with the other side of the dielectric PET layer.[26] A detailed methodology for non contact impedance in 
dielectric microdevice was published and a procedure was proposed to eliminate the contribution of the surronding PET layer comprised between the two embedded microelectrodes.[29],[30] This procedure enables a clear enhancement of the microchannel impedance contribution from the microchip global impedance. The non-contact geometry was previously tested for adsorption monitoring of BSA protein on photoablated PET [31] and for testing the biomolecular recognition between two proteic ligands i.e BSA adsorbed on PET and the corresponding antibodies Ab-BSA. [32]

However, in this paper the reaction takes place not on the PET substrate but on superparamagnetic beads immobilised in the detection zone.[33] Conversely to previous work [34] where microchannel impedance variation was monitored during enzymatic conversion of an enzymatic substrate, the present paper concerns the calibration of the detection scheme by using the microchannel conductivity which is determined through the cell constant accurately determined for this goal. The biological model proposed is the determination of dephosphorylation rate constant of the complexes enzyme-beads-organic phosphate measured using three adenosine phosphate biomolecules such as adenosine monoesterphosphate (AMP), adenosine diphosphate (ADP), adenosine triphosphate (ATP) that occurs on alkaline-phosphatase-linked superparamagnetic-beads in polymer microchannel. Indeed, the possibility to distinguish between the dephosphorylation rate constants for these enzyme phosphate complexes having close molecular structures is also evidenced.

\section{Experimental}

\subsection{Chemicals}

Adenosine monophosphate (AMP), adenosine diphosphate (ADP) and adenosine triphosphate (ATP) were purchased from Sigma Aldrich; 2-methylaminoethanol (MAE) was from Fluka Analytical. Magnesium chloride, sodium chloride, Tris(hydroxymethyl)aminomethane (Tris) were purchased from Sigma Aldrich. The washing buffer was made of $100 \mathrm{mM}$ Tris supplemented with $500 \mathrm{mM} \mathrm{NaCl}$. The substrate buffer was $100 \mathrm{mM}$ 2-methylaminoethanol with $2 \mathrm{mM} \mathrm{MgCl}_{2}$. Washing and substrate buffers were adjusted to $\mathrm{pH} 9$ with $\mathrm{HCl}$ and $\mathrm{NaOH}$. The organic phosphates were diluted in the substrate buffer: 16.1 mM AMP, 10.6 mM ADP, 11.7 mM ATP. Deionized water was 
used as regeneration solution. Alkaline Phosphatase at $3 \mathrm{mg} \mathrm{mL}^{-1}$ was from intestine of veal (Boehringer, Mannhein). Microbeads $1.8 \mu \mathrm{m}$ (Dynabeads) were purchased from Invitrogen France. The microbeads concentration was equal to $10 \mathrm{mg} \cdot \mathrm{mL}^{-1}$ with $4 \times 10^{8}$ microbeads per milliliter in phosphate buffer saline (PBS), $\mathrm{pH} 7.4$, containing $0.1 \% \mathrm{BSA}$ and $0.02 \% \mathrm{NaN}_{3}$.

\subsection{Microchannel Networks}

The non contact microchip device used in this work was described elsewhere. [20],[35] Briefly, admittance measurements were carried out through a polyethylene terephthalate (PET) microchannel photoablated having a cross-section shape with a depth of $50 \mu \mathrm{m}$, a top width of $100 \mu \mathrm{m}$ and a length of $1.4 \mathrm{~cm}$. The distance separation between both microelectrodes is $120 \mu \mathrm{m}$ edge to edge. The electrode fabrication is achieved using a carbon ink loaded with gold nanoparticles, thermally sealed by a polyethylene (10 $\mu \mathrm{m}) /$ polyethylene terephthalate $(25 \mu \mathrm{m})(\mathrm{PE} / \mathrm{PET})$ layer with a total thickness of $35 \mu \mathrm{m}$. The distance separation in the PET band between the two planar microelectrodes and the main microchannel is equal to $5 \mu \mathrm{m}$ and the detection surface area per microelectrode is $8.8 \times 10^{-4} \mathrm{~cm}^{2}$.

\subsection{Microchannel admittance measurement protocol}

The current measured is related to the total admittance of the microdevice. Measurements were performed using a frequency response analyzer (FRA 1255B, Solartron U.K.) associated with a dielectric interface 1296 (Solartron, U.K.) which extends the frequency range from $1 \mathrm{~Hz}$ to $10 \mathrm{MHz}$. Experiments were performed using the company-made software SMaRT. Electric admittance spectroscopy measurements have been performed by applying a $3 \mathrm{~V}$ ac voltage amplitude through the microelectrodes at $1 \mathrm{MHz}$ fixed frequency. To analyze these results, a physical model displayed on Figure 1 is used as described previously.[29]

\section{Results and discussion}

\subsection{Microchannel conductivity without direct electrical contact}

The characteristics of this kind of interface with an insulated layer sandwiched between two galvanic isolated microelectrodes can be represented as a dielectric system with, on the one 
part of the thin polymer layer, electronic charges on microelectrodes and, on the other part, ionic charges in the microchannel. An electrical equivalent circuit can be drafted, considering admittances for each part of the microdevice as displayed in Figure 1. The global admittance, $Y_{\mathrm{G}}$, through the microdevice using free contact microelectrodes configuration, is given by the sum:

$$
Y_{G}(\omega)=Y_{1}(\omega)+Y_{2}(\omega)
$$

wherein $\omega$ is the angular frequency $\left(\operatorname{rad~s}^{-1}\right)$, defined by $\omega=2 \pi f$, where $f$ is the frequency $(\mathrm{Hz})$.

The detailled admittances $Y_{1}$ and $Y_{2}$ in equations 2 and 3 can be decomposed for each branch i.e. through the microchannel and through the direct coupling between the two embedded microelectrodes, respectively.

$$
Y_{1}(\omega)=\frac{1}{\frac{2}{j \omega C_{P E T, 5 \mu m}}+\frac{2}{(j \omega)^{\alpha_{\text {int }}} Q_{\mathrm{int}}}+\frac{R_{S}}{1+j \omega C_{C} R_{S}}}
$$

and

$$
Y_{2}(\omega)=j \omega C_{P E T, 120 \mu m}
$$

The $5 \mu \mathrm{m}$ thickness of the PET layer isolated microelectrodes from the small channel makes it to behave as a capacitor $C_{\mathrm{PET}, 1}$ and was equal to $14 \times 10^{-11} \mathrm{~F}$. The $120 \mu \mathrm{m}$ thickness of the PET layer separated the two microelectrodes also behaves as a capacitor $C_{\mathrm{PET}, 2}$ and was equal to $8 \times 10^{-13} \mathrm{~F}$. The PET/ microchannel interface is represented by a non ideal capacitor which is defined by a constant phase element CPE with $Q_{\text {int }}$ and $\alpha_{\text {int }}$ being the CPE element and the CPE exponent, respectively. The CPE exponent $\alpha_{\text {int }}$ takes into account the role of the photoablated PET surface at the microchannel bottom. In previous work alpha $\alpha_{\text {int }}$ was found equal to 0.5 and $Q_{\text {int }}=4.7 \times 10^{-8} \Omega^{-1} \cdot \mathrm{s}^{-\alpha}$.[29] The change on the interfacial CPE parameter is neglected to the aim of this paper as the organic phosphate 
dephosphorylation occurs on Alcaline Phosphatase linked beads and not on the PET photoablated surface. [31],[32],[36]

In the microchannel, the admittance $Y_{\mathrm{CH}}$ is represented by a parallel association $R_{\mathrm{S}} / / C_{\mathrm{C}}$ circuit. The resistance, $R_{\mathrm{S}}$, is characteristic to the electrolyte resistance while $C_{\mathrm{C}}$ is an intrinsic parameter linked to the cell geometry named the cell capacitance. This latter was estimated to $C_{\mathrm{C}}=3 \times 10^{-13} \mathrm{~F}$. [29],[32] As mentioned previously, the target application is the real-time monitoring of the microchannel conductivity that is given through the relative variation of the conductance ( $Y_{1}$ real admittance part, $\left.\Delta \mathfrak{R e}\left(Y_{1}\right)\right)$. Indeed, the derivative expression of equation 2 leads to equation 4, in which conductance is conversely proportional to the microchannel resistance at fixed frequency.

$$
\Delta \mathfrak{R} e\left(Y_{1}\right)=\Delta\left[\frac{1}{R_{S}}\right]
$$

This can finally lead to an analytical expression for determining the microchannel conductivity variation at fixed frequency taking into account the cell constant, $K$, as follows:

$$
\Delta \sigma=K \Delta \mathfrak{R} e\left(Y_{1}\right)
$$

where $K$ is the cell constant equals to $5 \times 10^{3} \mathrm{~m}^{-1}$ and $\Delta \sigma$ expressed in $\mathrm{S} \mathrm{m}^{-1}$.

\subsection{Kinetics of enzymatic conversion of organic phosphate}

Scheme 1 presents in brief the catalytic hydrolysis mechanism for organic phosphate involving intermediate phosphorylation of ALP enzyme, $E$, where $[E-\mathrm{ROP}]^{\#}$ and $[E-\mathrm{Pi}]^{\#}$ are the Michaelis complex and the phosphoryl enzyme, respectively. The reaction products $R \mathrm{O}-\mathrm{H}$ and $\mathrm{Pi}$ are the corresponding alcohol (from substrates which are chemically different via $R$ in $R \mathrm{O}-\mathrm{P}$ ) and the released inorganic phosphate, respectively. As displayed in scheme 1 , the ratio of two kinetic constants $k_{1} / k_{-1}$ is an equilibrium constant because $k_{1}$ is known as a diffusion-controlled rate $\left(10^{9}-10^{10} \mathrm{M}^{-1} \mathrm{~s}^{-1}\right)$.[37] The last step constitutes the ratedetermining enzymatic step as expressed in the following equation 6 since hydrolysis of the phosphoryl enzyme is the rate determining step. 
$v=\frac{d[P i]}{d t}=\frac{k_{2} k_{3}}{k_{2}+k_{3}}[E-R O-P]^{\neq}$

where $k_{3}$ and $k_{2}$ are the constants of the phosphorylation and dephosphorylation rates, respectively.

In order to determine the dephosphorylation rate with the following organic phosphate biomolecules: AMP, ADP, ATP the procedure described below was followed for various concentrations of ALP. The experimental data consist, for each organic phosphate concentration, in a set of conductivity experimental curves that were recorded as a function of the measurement time, $t$. Samples were introduced by capillarity in the PET microchannel with a total volume of $80 \mathrm{~nL}$. The detection procedure of the microchannel conductivity was preferred at $1 \mathrm{MHz}$ fixed frequency (fast acquisition) with time until a baseline between each step. As displayed in Figure 1, a permanent magnet located above the conductometry sensor was switched on the position ON. [33] The procedure for monitoring experiments of ALP catalyzing dephosphorylation was divided in three steps (see Figure 2). The step one consisted in measuring the conductance for microchannel filled with substrate buffer $\left(100 \mathrm{mM}\right.$ MAE and $\left.0.2 \mathrm{mM} \mathrm{MgCl}_{2}\right)$. Then, in step two, the microchannel was filled with beads linked ALP enzyme. For instance, an ALP- $\mu$ beads sample (see Table S1 in supplementary material) was introduced on the channel and the measurement protocol described above was followed until a baseline was reached. The step three consisted in loading the channel with organic phosphate sample as illustrated with ADP in Figure 2. Magnification of step 3 as it appears on Figure 3 highlights the net increase of the measured conductance with time. A normalization step was performed by subtracting the background conductivity $\sigma_{0}$ at $t_{0}$. For that purpose, $\Delta \sigma$ variation against time during catalytic dephosphorylation of ADP is plotted from typical $\Delta \sigma=\mathrm{f}(t)$. At the end, the initial rate, $v_{i}$-slope, of $\Delta \sigma$ variation in time (see equation 7 and Figure 3) gives information about the conversion kinetics of phosphate biomolecule.

$$
v_{i}=\frac{d \Delta \sigma}{d t}
$$

where the unit is in $\mathrm{S} \mathrm{m}^{-1} \mathrm{~s}^{-1}$. 
Obviously, the conductivity variation in presence of ALP- $\mu$ bead is due to the ionic charge increase in microchannel solution when the catalytic hydrolysis starts. In fact, when the phosphoryl complex is hydrolysed, the substrate (ADP) level decays and product amounts (AMP and phosphate ion) increase (see Scheme 1 and Figure 3). The experimental protocol described in Figure 2 and Figure 3 was performed for the three organic phosphate biomolecules in presence of various concentration for ALP- $\mu$ beads (see Table S1 in supplementary material). All data rates obtained, including standard deviations, are listed in Table S1 in the supplementary material. The mean values of dephosphorylation kinetics rate for each used organic phosphate was obtained through the $v_{i}$-slope listed in Table 1.

The dephosphorylation rate constant, $k_{2}$, is obtained by plotting the initial rate ( $v_{\mathrm{i}}$-slope in Table 1) against the total enzyme concentration. As displayed in Figure 4, a pseudo-firstorder kinetic behaviour can be observed due to the low enzyme concentration that is negligible in comparison with the high organic phosphate concentration (see Table 1). The linear fits obtained using equation 8 have a slope which corresponds to the dephosphorylation rate constant, $k_{2}$, and $k_{0}$ without enzyme.

$v=k_{2}[A L P]+k_{0}$

with $k_{2}$ in $\mathrm{S} \mathrm{m}^{-1}(\mathrm{pM} \mathrm{s})^{-1}$ and $k_{0}$ in $\mathrm{S} \mathrm{m}^{-1} \mathrm{~s}^{-1}$.

The obtained values for $k_{2}$ and $k_{0}$ listed in table 2 have been converted using the method sensitivity $\left(1 \mu \mathrm{S} \mathrm{m}^{-1} \mathrm{pM}^{-1}\right)$ in order to compare these values with standard units i.e. in $\mathrm{s}^{-1}$ and $\mathrm{pM}^{-1} \cdot \mathrm{s}^{-1}$, respectively. The obtained values are in agreement with those published and obtained with optical methods. [38],[39] Assuming that $k_{2}$ is negligible in comparison with $k_{3}$ (see equation 6), $k_{2}$ becomes equivalent to the hydrolysis catalytic constant, $k_{\text {cat }}$. The means values of $k_{2, \text { AMP }}\left(39.4 \mathrm{~s}^{-1}\right)>k_{2}$, ADP, $>\left(32.8 \mathrm{~s}^{-1}\right)>k_{2}$, ATP, $\left(30.2 \mathrm{~s}^{-1}\right)$ are close in the adenosine series and show steric hindrance effect according to the number phosphate groups (1, 2 and 3), respectively. 


\section{Conclusions}

Microchannel conductivity detection using electric admittance on polymer coated microelectrodes in microchip is a very sensitive method for monitoring chemical reaction such as dephosphorylation of organic phosphate in low volume reagent. This has been illustrated with a presented methodology for monitoring enzyme kinetics with ultralow (45 $\mathrm{fM}$ ) concentration of ALP enzyme added in the microchannel. Detection through this microdevice permits small consumption of reagents in comparison with other assays. Measurement of kinetic rates can be measured after a few seconds for an assay in comparison with the traditional ELISA microtitration plates where the data processing is long. Furthermore, this detection scheme could be extended for any enzymatic substrates since the detected product does not need to be a chromophoric or electroactive species. The different dephosphorylation kinetics rate obtained with adenosine phosphate substrates on alcaline phosphatase-linked beads underline sensitivity and selectivity of the method. This opens a new way for fast medical diagnostics in low volume reagent or for biological screening of ligands of interest such as natural phosphoproteins having no chromogenic or electrochemical property. [40]

\section{Acknowledgements}

The authors thank Prof Hubert Girault and Dr Philippe Flückiger for allowing them access to experimental facilities at the EPFL center of MicroNano Technology, Lausanne. 


\section{References}

[1] J.M. Ruano-Lopez, M. Agirregabiria, G. Olabarria, D. Verdoy, D.D. Bang, M. Bu, A. Wolff, A. Voigt, J.A. Dziuban, R. Walczak, J. Berganzo, Lab on a Chip, 9 (2009) 14951499.

[2] V. Oncescu, D. O'Dell, D. Erickson, Lab on a Chip, 13 (2013) 3232-3238.

[3] V. Oncescu, M. Mancuso, D. Erickson, Lab on a Chip, (2014).

[4] J.S. Rossier, M.A. Roberts, R. Ferrigno, H.H. Girault, Analytical Chemistry, 71 (1999) 4294-4299.

[5] J.S. Rossier, R. Ferrigno, H.H. Girault, Journal of Electroanalytical Chemistry, 492 (2000) 15-22.

[6] H. Wang, Y. Liu, C. Liu, J. Huang, P. Yang, B. Liu, Electrochemistry Communications, 12 (2010) 258-261.

[7] D.W.M. Arrigan, Analyst, 129 (2004) 1157-1165.

[8] M.E. Sandison, J.M. Cooper, Lab on a Chip, 6 (2006) 1020-1025.

[9] S. Méance, K. Papin, J. Gamby, G. Aubry, Q. Kou, A.-M. Haghiri-Gosnet, Microelectronic Engineering, 88 (2011) 1798-1800.

[10] A.J. Wain, Chapter 2 Electrochemistry at nanoelectrodes, in: Electrochemistry: Volume 12, The Royal Society of Chemistry, 2014, pp. 44-86.

[11] M. Faure, A. Pallandre, S. Chebil, I. Le Potier, M. Taverna, B. Tribollet, C. Deslouis, A.-M. Haghiri-Gosnet, J. Gamby, Lab on a Chip, 14 (2014) 2800-2805.

[12] S. Méance, J. Gamby, M. Faure, Q. Kou, A.-M. Haghiri-Gosnet, Talanta, 129 (2014) $150-154$.

[13] H. Hinkers, C. Sundermeier, R. Lürick, F. Walfort, K. Cammann, M. Knoll, Sensors and Actuators B: Chemical, 27 (1995) 398-400.

[14] Y. Liu, H. Wang, J. Huang, J. Yang, B. Liu, P. Yang, Analytica Chimica Acta, 650 (2009) 77-82.

[15] A. Meunier, R. Fulcrand, F. Darchen, M. Guille Collignon, F. Lemaitre, C. Amatore, Biophysical Chemistry, 162 (2012) 14-21.

[16] S.K. Jha, R. Chand, D. Han, Y.-C. Jang, G.-S. Ra, J.S. Kim, B.-H. Nahm, Y.-S. Kim, Lab on a Chip, 12 (2012) 4455-4464.

[17] J. Janata, Chemical Reviews, 90 (1990) 691-703.

[18] T.-Y. Chiang, C.-H. Lin, RSC Advances, 4 (2014) 379-385.

[19] N. Ibáñez-García, M. Baeza, M. Puyol, R. Gómez, M. Batlle, J. Alonso-Chamarro, Electroanalysis, 22 (2010) 2376-2382.

[20] J. Vacík, J. Zuska, I. Muselasová, Journal of Chromatography A, 320 (1985) 233-240.

[21] A.J. Zemann, E. Schnell, D. Volgger, G.K. Bonn, Analytical Chemistry, 70 (1998) 563-567.

[22] J.A. Fracassi da Silva, N. Guzman, C.L. do Lago, J. Chromatogr. A, 942 (2002) 249258.

[23] J.G.A. Brito-Neto, J.A. Fracassi da Silva, L. Blanes, C.L. do Lago, Electroanalysis, 17 (2005) 1198-1206.

[24] J. Lichtenberg, N.F. de Rooij, E. Verpoorte, Electrophoresis, 23 (2002) 3769-3780.

[25] M. Vazquez, C. Frankenfeld, W.K.T. Coltro, E. Carrilho, D. Diamond, S.M. Lunte, Analyst, 135 (2010) 96-103.

[26] J. Gamby, J.-P. Abid, H.H. Girault, Journal of the American Chemical Society, 127 (2005) 13300-13304. 
[27] J. Gamby, M. Lazerges, C. Pernelle, H. Perrot, H.H. Girault, B. Tribollet, Lab on a Chip, 7 (2007) 1607-1609.

[28] J. Gamby, J.P. Abid, M. Abid, J.P. Ansermet, H.H. Girault, Analytical Chemistry, 78 (2006) 5289-5295.

[29] M. Kechadi, J. Gamby, L. Chaal, H. Girault, B. Saidani, B. Tribollet, Electrochimica Acta, 105 (2013) 7-14.

[30] M. Kechadi, J. Gamby, L. Chaal, B. Saidani, B. Tribollet, Journal of Flow Chemistry, 3 (2013) 81-86.

[31] M. Kechadi, L. Chaal, B. Tribollet, J. Gamby, Analyst (Cambridge, U. K.), 139 (2014) 1492-1497.

[32] M. Kechadi, B. Sotta, L. Chaal, B. Tribollet, J. Gamby, Analyst, 139 (2014) 31153121.

[33] F. Sarreshtedari, H. Kokabi, J. Gamby, K.A. Ngo, H.-J. Krause, M. Fardmanesh, Journal of Electrical Engineering, 63 (2012) 27-30.

[34] M. Faure, B. Sotta, J. Gamby, Biosens Bioelectron, 58C (2014) 61-67.

[35] J. Gamby, A. Rudolf, M. Abid, H.H. Girault, C. Deslouis, B. Tribollet, Lab on a Chip, 9 (2009) 1806-1808.

[36] M. Kechadi, M. Faure, B. Sotta, J. Gamby, Journal of Flow Chemistry, 4 (2014) 6671.

[37] C.P. Andrieux, B. Limoges, D. Marchal, J.-M. Savéant, Analytical Chemistry, 78 (2006) 3138-3143.

[38] C. Lazdunski, M. Lazdunski, European Journal of Biochemistry, 7 (1969) 294-300.

[39] M. Kulp, M. Kaljurand, Journal of Chromatography A, 1032 (2004) 305-312.

[40] K.D. Green, M.K.H. Pflum, Journal of the American Chemical Society, 129 (2006) 10-11. 


\section{Scheme caption}

Scheme 1. Simplified mechanism of alkaline phosphatase ALP (E) for catalytic hydrolysis of organic phosphate compounds (RO-P) involving intermediate phosphorylation of $E$, where $[E-\mathrm{ROP}]^{\#}$ and $[E-\mathrm{Pi}]^{\#}$ are the Michaelis complex and the phosphoryl enzyme, respectively. 


\section{Table captions}

Table 1: The obtained $v_{\mathrm{i}}$-slopes according to the fit using equation 7 (see table $\mathrm{S} 1$ in the supplementary material for more details).

Table 2: The obtained values for $k_{2}$ and $k_{0}$ according to the fit using equation 8 . 


\section{Figure captions}

Fig. 1: Schematic description of the small conductometric sensor in PET microchip through the dielectric microelectodes/ PET/ microchannel interfaces with an superimposed equivalent electrical circuit.

Fig. 2: Measurement protocol for catalytic ADP dephosphorylation. In step 1: Conductivity level for microchannel filled with substrate buffer. In step 2: Conductivity level for microchannel filled with ALP-linked beads (0.045 pM ALP- $\mu$ beads, see Table S1 in supplementary material). In step 3: Conductivity level for microchannel filled with 16.1 mM ADP as organic phosphate.

Fig 3: Magnification of step 3 where the microchannel conductivity was normalized with $\sigma_{0}$ (background conductivity) at $t_{0}$ (reaction starts) when $16.1 \mathrm{mM}$ ADP concentration was in presence of $0.045 \mathrm{pM}$ ALP- $\mu$ beads.

Fig. 4: Calibration curves of dephosphorylation rate of ALP- $\mu$ beads for AMP, ADP, ATP substrates. The maximum rate, $v_{\mathrm{i}}$-slope, is plotted against ALP concentration with a fixed organic phosphate concentration. Each point represents the mean of experiments with ALP concentrations (from $0.045 \mathrm{pM}$ to $1.21 \mathrm{pM}$ ). The linear fits (solid lines) are performed using Eq. 8 (in the text). 
Scheme 1

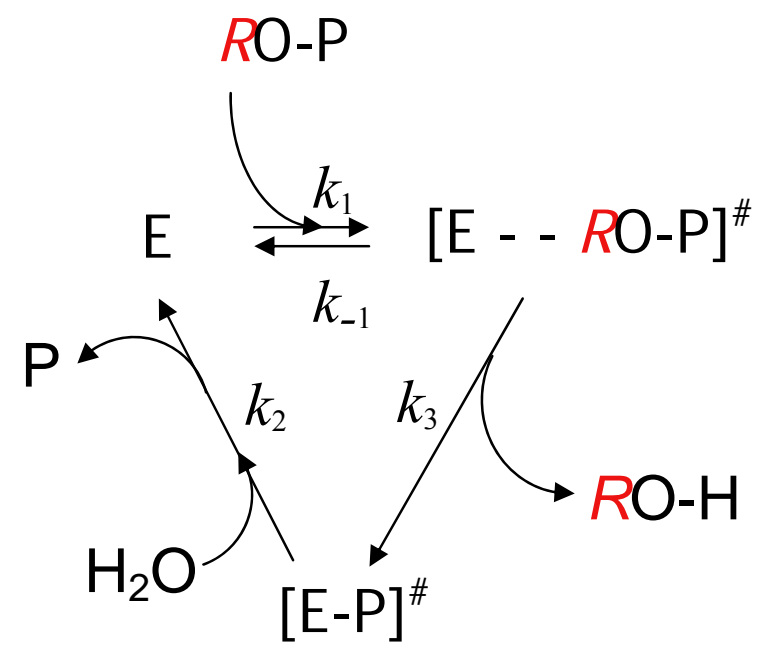


Figure 1

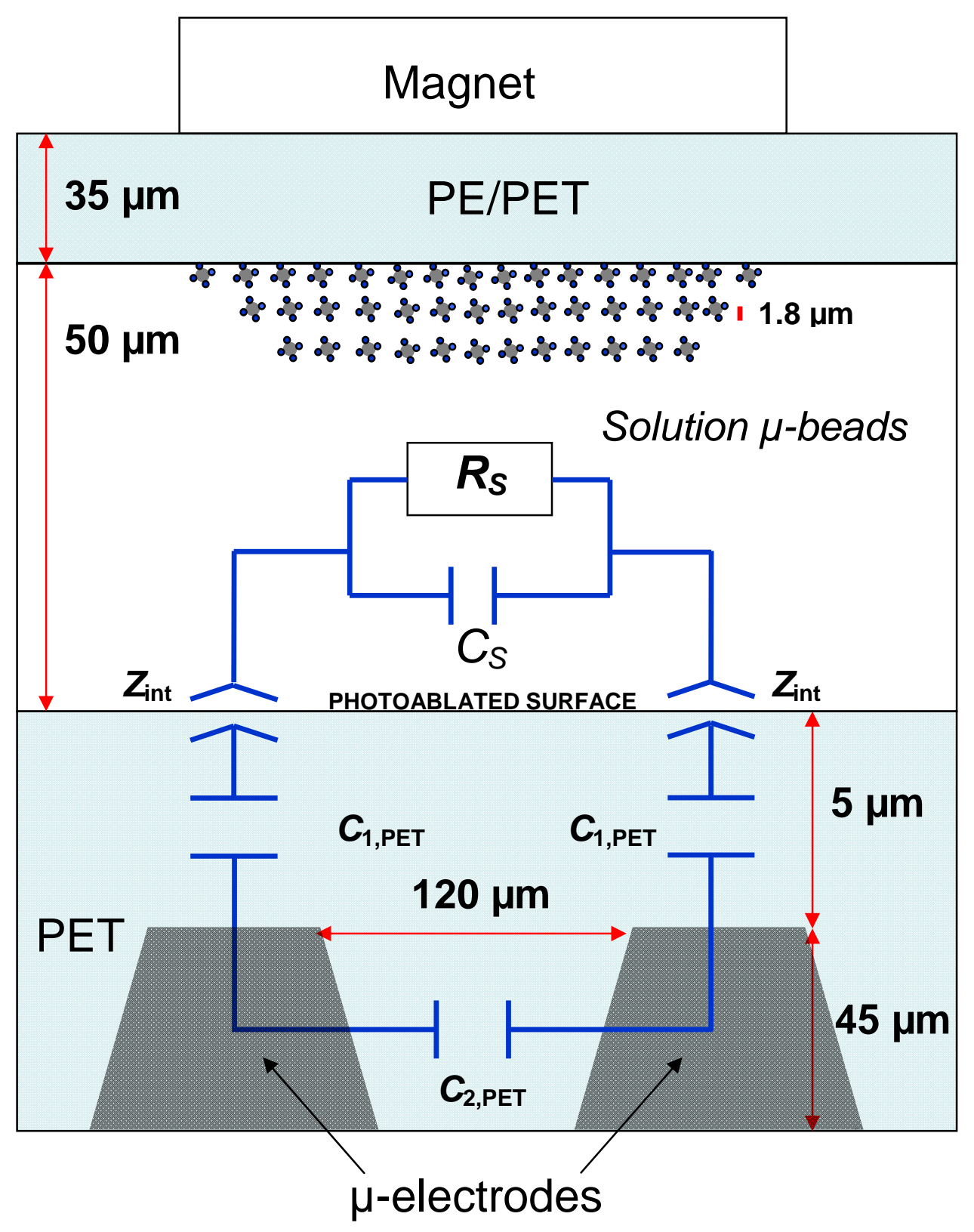


Figure 2

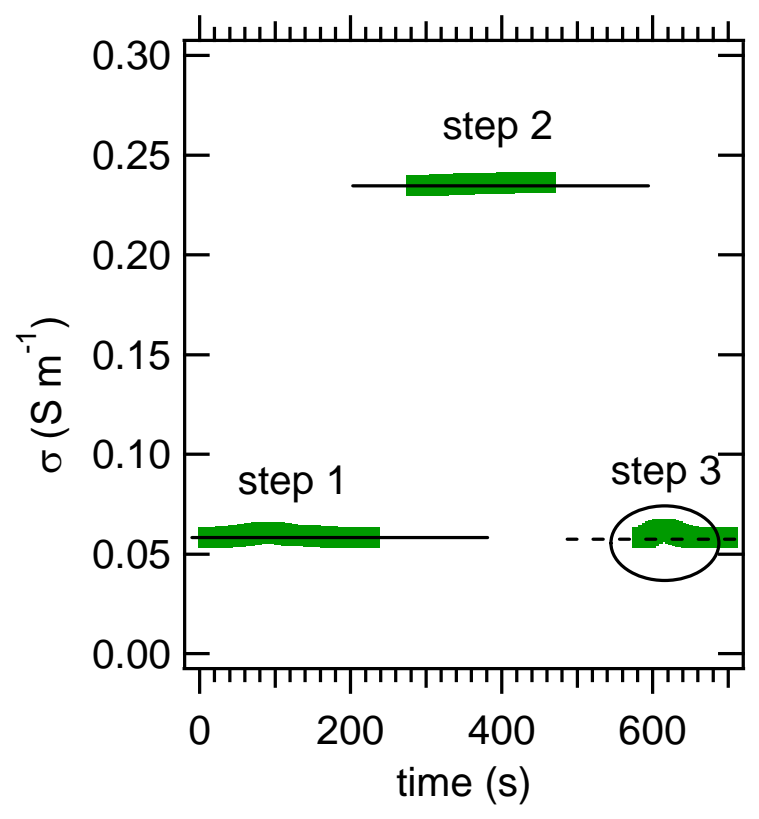


Figure 3

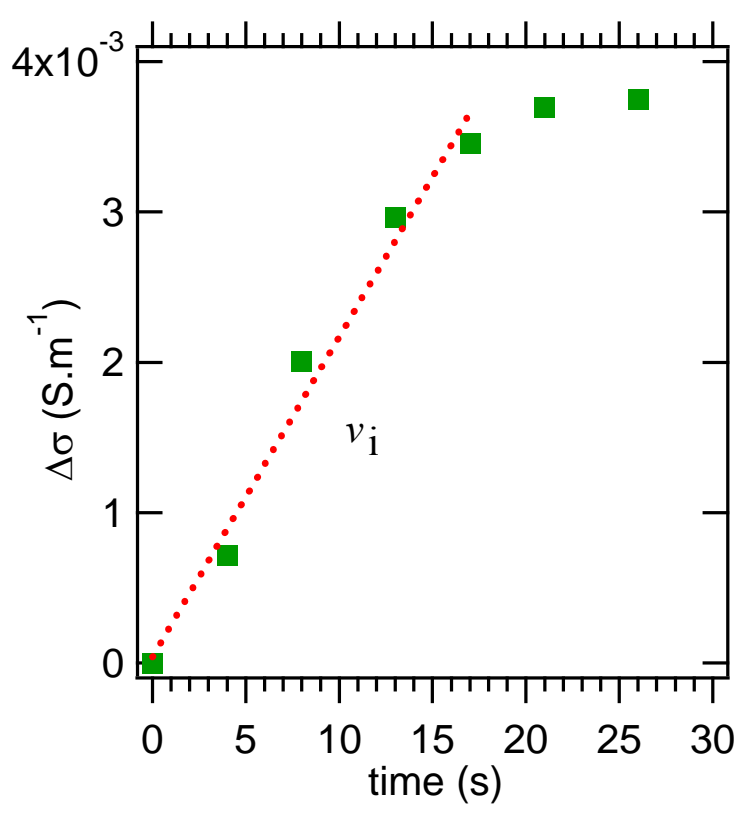


Figure 4

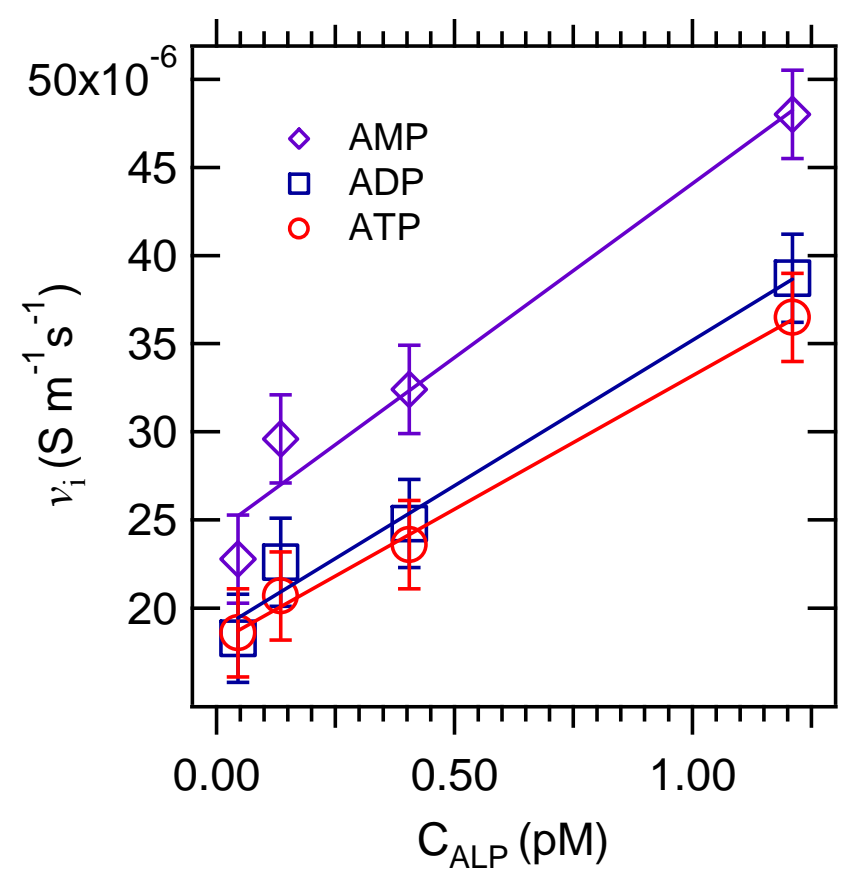


Table 1

\begin{tabular}{ccccccc}
\hline \multirow{2}{*}{$\begin{array}{c}v_{\mathrm{i}}, \text { initial rate } \\
\times 10^{-5}\left(\mathrm{~S} \mathrm{~m}^{-1} \mathrm{~s}^{-1}\right)\end{array}$} & & \multicolumn{4}{c}{$\begin{array}{c}\text { ALP Enzyme concentration } \\
\left(\times 10^{-12} \mathrm{M}\right)\end{array}$} \\
\cline { 3 - 7 } & & & 1.21 & 0.405 & 0.135 & 0.045 \\
\hline \begin{tabular}{c} 
Organic \\
phosphate \\
\cline { 3 - 7 }$\left(\times 10^{-3} \mathrm{M}\right)$
\end{tabular} & 16.1 & AMP & 4.58 & 3.24 & 2.96 & 2.28 \\
\cline { 2 - 7 } & 10.6 & ADP & 3.87 & 2.48 & 2.26 & 1.83 \\
\hline
\end{tabular}


Table 2

\begin{tabular}{ccc}
\hline $\begin{array}{c}\text { Kinetic constants of } \\
\text { enzymatic conversion }\end{array}$ & $\begin{array}{c}k_{2} \\
\left(\mathrm{~s}^{-1}\right)\end{array}$ & $\begin{array}{c}k_{0} \\
\left(\mathrm{M}^{-1} \mathrm{~s}^{-1}\right)\end{array}$ \\
\hline AMP & 39.4 & 48.6 \\
\hline ADP & 32.8 & 37.4 \\
\hline ATP & 30.2 & 36.2 \\
\hline
\end{tabular}




\section{References}

[1] J.M. Ruano-Lopez, M. Agirregabiria, G. Olabarria, D. Verdoy, D.D. Bang, M. Bu, A. Wolff, A. Voigt, J.A. Dziuban, R. Walczak, J. Berganzo, Lab on a Chip, 9 (2009) 14951499.

[2] V. Oncescu, D. O'Dell, D. Erickson, Lab on a Chip, 13 (2013) 3232-3238.

[3] V. Oncescu, M. Mancuso, D. Erickson, Lab on a Chip, (2014).

[4] J.S. Rossier, M.A. Roberts, R. Ferrigno, H.H. Girault, Analytical Chemistry, 71 (1999) 4294-4299.

[5] J.S. Rossier, R. Ferrigno, H.H. Girault, Journal of Electroanalytical Chemistry, 492 (2000) 15-22.

[6] H. Wang, Y. Liu, C. Liu, J. Huang, P. Yang, B. Liu, Electrochemistry Communications, 12 (2010) 258-261.

[7] D.W.M. Arrigan, Analyst, 129 (2004) 1157-1165.

[8] M.E. Sandison, J.M. Cooper, Lab on a Chip, 6 (2006) 1020-1025.

[9] S. Méance, K. Papin, J. Gamby, G. Aubry, Q. Kou, A.-M. Haghiri-Gosnet, Microelectronic Engineering, 88 (2011) 1798-1800.

[10] A.J. Wain, Chapter 2 Electrochemistry at nanoelectrodes, in: Electrochemistry: Volume 12, The Royal Society of Chemistry, 2014, pp. 44-86.

[11] M. Faure, A. Pallandre, S. Chebil, I. Le Potier, M. Taverna, B. Tribollet, C. Deslouis, A.-M. Haghiri-Gosnet, J. Gamby, Lab on a Chip, 14 (2014) 2800-2805.

[12] S. Méance, J. Gamby, M. Faure, Q. Kou, A.-M. Haghiri-Gosnet, Talanta, 129 (2014) $150-154$.

[13] H. Hinkers, C. Sundermeier, R. Lürick, F. Walfort, K. Cammann, M. Knoll, Sensors and Actuators B: Chemical, 27 (1995) 398-400.

[14] Y. Liu, H. Wang, J. Huang, J. Yang, B. Liu, P. Yang, Analytica Chimica Acta, 650 (2009) 77-82.

[15] A. Meunier, R. Fulcrand, F. Darchen, M. Guille Collignon, F. Lemaitre, C. Amatore, Biophysical Chemistry, 162 (2012) 14-21.

[16] S.K. Jha, R. Chand, D. Han, Y.-C. Jang, G.-S. Ra, J.S. Kim, B.-H. Nahm, Y.-S. Kim, Lab on a Chip, 12 (2012) 4455-4464.

[17] J. Janata, Chemical Reviews, 90 (1990) 691-703.

[18] T.-Y. Chiang, C.-H. Lin, RSC Advances, 4 (2014) 379-385.

[19] N. Ibáñez-García, M. Baeza, M. Puyol, R. Gómez, M. Batlle, J. Alonso-Chamarro, Electroanalysis, 22 (2010) 2376-2382.

[20] J. Vacík, J. Zuska, I. Muselasová, Journal of Chromatography A, 320 (1985) 233-240.

[21] A.J. Zemann, E. Schnell, D. Volgger, G.K. Bonn, Analytical Chemistry, 70 (1998) 563-567.

[22] J.A. Fracassi da Silva, N. Guzman, C.L. do Lago, J. Chromatogr. A, 942 (2002) 249258.

[23] J.G.A. Brito-Neto, J.A. Fracassi da Silva, L. Blanes, C.L. do Lago, Electroanalysis, 17 (2005) 1198-1206.

[24] J. Lichtenberg, N.F. de Rooij, E. Verpoorte, ELECTROPHORESIS, 23 (2002) 37693780 .

[25] M. Vazquez, C. Frankenfeld, W.K.T. Coltro, E. Carrilho, D. Diamond, S.M. Lunte, Analyst, 135 (2010) 96-103. 
[26] J. Gamby, J.-P. Abid, H.H. Girault, Journal of the American Chemical Society, 127 (2005) 13300-13304.

[27] J. Gamby, M. Lazerges, C. Pernelle, H. Perrot, H.H. Girault, B. Tribollet, Lab on a Chip, 7 (2007) 1607-1609.

[28] J. Gamby, J.P. Abid, M. Abid, J.P. Ansermet, H.H. Girault, Analytical Chemistry, 78 (2006) 5289-5295.

[29] M. Kechadi, J. Gamby, L. Chaal, H. Girault, B. Saidani, B. Tribollet, Electrochimica Acta, 105 (2013) 7-14.

[30] M. Kechadi, J. Gamby, L. Chaal, B. Saidani, B. Tribollet, Journal of Flow Chemistry, 3 (2013) 81-86.

[31] M. Kechadi, L. Chaal, B. Tribollet, J. Gamby, Analyst (Cambridge, U. K.), 139 (2014) 1492-1497.

[32] M. Kechadi, B. Sotta, L. Chaal, B. Tribollet, J. Gamby, Analyst, 139 (2014) 31153121.

[33] F. Sarreshtedari, H. Kokabi, J. Gamby, K.A. Ngo, H.-J. Krause, M. Fardmanesh, Journal of Electrical Engineering, 63 (2012) 27-30.

[34] M. Faure, B. Sotta, J. Gamby, Biosens Bioelectron, 58C (2014) 61-67.

[35] J. Gamby, A. Rudolf, M. Abid, H.H. Girault, C. Deslouis, B. Tribollet, Lab on a Chip, 9 (2009) 1806-1808.

[36] M. Kechadi, M. Faure, B. Sotta, J. Gamby, Journal of Flow Chemistry, 4 (2014) 6671.

[37] C.P. Andrieux, B. Limoges, D. Marchal, J.-M. Savéant, Analytical Chemistry, 78 (2006) 3138-3143.

[38] C. Lazdunski, M. Lazdunski, European Journal of Biochemistry, 7 (1969) 294-300.

[39] M. Kulp, M. Kaljurand, Journal of Chromatography A, 1032 (2004) 305-312.

[40] K.D. Green, M.K.H. Pflum, Journal of the American Chemical Society, 129 (2006) $10-11$. 